Review Article

\title{
Effectiveness and Safety of Acupuncture and Moxibustion for Primary Dysmenorrhea: An Overview of Systematic Reviews and Meta-Analyses
}

\author{
Jun Yang $\left(\mathbb{D},{ }^{1}\right.$ Jun Xiong $\mathbb{D}^{2},{ }^{2}$ Ting Yuan $\mathbb{D}^{1},{ }^{1}$ Xue Wang $\mathbb{D},{ }^{1}$ Yunfeng Jiang $\mathbb{D},^{2}$ \\ Xiaohong Zhou $\mathbb{D}^{2},{ }^{2}$ Kai Liao $\left.\mathbb{D}\right)^{2}$ and Lingling $\mathrm{Xu} \mathbb{D}^{2}$ \\ ${ }^{1}$ Jiangxi University of TCM, Nanchang, Jiangxi, China \\ ${ }^{2}$ The Affiliated Hospital of Jiangxi University of TCM, Nanchang, Jiangxi, China \\ Correspondence should be addressed to Jun Xiong; xiongjun196071@163.com
}

Received 4 January 2020; Revised 28 February 2020; Accepted 30 March 2020; Published 29 April 2020

Academic Editor: Morry Silberstein

Copyright (c) 2020 Jun Yang et al. This is an open access article distributed under the Creative Commons Attribution License, which permits unrestricted use, distribution, and reproduction in any medium, provided the original work is properly cited.

\begin{abstract}
Background. Acupuncture and moxibustion have been accepted as treatment options for primary dysmenorrhea (PD). So far, several systematic reviews (SRs) and meta-analyses (MAs) have reported on the efficacy and safety of acupuncture and moxibustion in treating PD. Objectives. The aim of this study was to critically summarize the evidence from relevant SRs and MAs reporting on the efficacy and safety of acupuncture and moxibustion in treatment of PD. Materials and Methods. Seven electronic databases, including Cochrane Database of Systematic Reviews, EMBASE, PubMed, SinoMed, China National Knowledge Infrastructure (CNKI), Chinese Science and Technology Periodical Database (VIP), and Wanfang database, were systematically searched. SRs or MAs about acupuncture for PD published up to May 2019 were included in the analysis. More than two authors independently assessed the quality of the evidence by AMSTAR2, PRISMA, PRISMA-A, and GRADE approach. Results. A total of 28 SRs and MAs, 281 original studies, reporting on 26,459 female patients were analyzed. The majority of the SRs were of moderate reporting quality and poor methodological quality. Moderate-quality evidence suggested that acupuncture and moxibustion were more effective compared to indomethacin or Fenbid in treating PD. Low-quality evidence suggested that, compared to NSAIDs, acupuncture and moxibustion could relieve pain with less adverse effects. Conclusion. Acupuncture and moxibustion seem to be effective and safe approaches in treatment of PD; yet, the methodological quality of most of the studies and the quality of evidence were low. Thus, additional studies are required to further confirm these results.
\end{abstract}

\section{Introduction}

Primary dysmenorrhea (PD) is a common gynecological disorder, mainly characterized by cramping pain in the lower abdomen that occurs before or during menstruation. Headache, nausea, vomiting, fatigue, irritability, diarrhea, and an overall feeling of discomfort are the common symptoms accompanying PD [1]. The disorder can significantly affect women's physical health and life quality [2]. In the USA, PD is responsible for the loss of 600 million work hours and two million dollars each year [3]. In China, the prevalence of dysmenorrhea is $30 \%$ $80 \%$, among which $53 \%$ is from PD and $15 \%$ from severe dysmenorrhea [4].
Nonsteroidal anti-inflammatory drugs (NSAIDs), oral contraceptive pills, or acupuncture are commonly used to alleviate the menstrual pain. Yet, drug therapy may lead to some adverse events, such as digestive disorders, headache, and drowsiness. In addition, $20 \%-25 \%$ of women do not respond well to these medications [5]. As nonpharmaceutical therapy, acupuncture stimulates the nervous system and release of endogenous substances, such as opioid peptides and serotonin, to improve symptoms [6, 7]. Moreover, moxibustion can regulate the levels of reproductive hormones to reduce the pain of dysmenorrhea [8]. Some studies have reported that the combination of acupuncture and moxibustion at SP6 
could effectively improve the uterine artery hemodynamics and hemorheology in patients, as well as regulate blood viscosity and erythrocyte aggregation degree to relieve the pain [9-12].

Systematic reviews (SRs), especially those combined with meta-analyses (MAs), are of essential importance in evaluating clinical efficacy and formulating clinical guidelines $[13,14]$. In their SR, Smith et al. have reported that current evidence cannot support the effectiveness of acupuncture in treating PD [15]. Moreover, Zhang et al. carried an overview to assess the effect of acupuncture and acupressure on PD using AMSTAR2 (A Measure Tool to Assess Systematic Reviews 2) and PRISMA (Preferred Reporting Items for Systematic Reviews and Meta-Analyses) tools [16-18]. They concentrated on acupuncture and acupressure, without referring to the moxibustion and quality of the available evidence. In addition, the results from SRs are conflicting, and the conclusions are limited. To overcome the limitations of an individual SR and to provide comprehensive evidence, an overview of multiple SRs, which is a new approach designed to synthesize the available results, is needed.

We enlarged the research source from seven databases and also considered the intervention of moxibustion so as to provide comprehensive evidence. Therefore, we conducted an overview to synthesize and critically appraise the available evidence on the effectiveness and safety of acupuncture and moxibustion for PD by using AMSTAR2, PRISMA, and GRADE (Grading of Recommendations Assessment, Development and Evaluation) approach [19].

\section{Materials and Methods}

2.1. Study Registration. The study has been registered in PROSPERO (http://www.crd.york.ac.uk/PROSPERO/ display_record.php?ID=CRD42015016795).

\subsection{Eligibility Criteria}

2.2.1. Types of Study. This SRs-MAs evaluate research articles written in Chinese and English reporting on effectiveness and safety of acupuncture and moxibustion for PD. Review articles, letters, conference papers, abstracts, protocols, and network meta analyses were excluded.

2.2.2. Types of Participants. We included female patients of reproductive age suffering from $\mathrm{PD}$. The definition of $\mathrm{PD}$ was based on cyclic pelvic pain during menstruation without any gynecological pathology, such as endometriosis, adenomyosis, or uterine myoma. Patients with secondary dysmenorrhea or serious medical conditions were excluded.

2.2.3. Criteria for Intervention. The interventions included needle acupuncture, electro-acupuncture, auricular acupuncture, moxibustion, acupressure, point injection, or any combination of the above.
2.2.4. Criteria for Comparison. We included western medicine, placebo, sham acupuncture, no treatment, or any combination of these.

2.2.5. Primary Outcome. The total effective rate [20] was selected as a primary outcome. It was calculated based on the ratio of the total number of those who were effectively cured and the total number of sick people [20].

2.2.6. Secondary Outcomes. Secondary outcomes were the following: clinical effective rate, visual analogue scale (VAS), adverse effects, quality of life, and symptom of dysmenorrhea. Clinical effective rate was calculated based on the ratio of the total number of people who responded well to therapy and the total number of sick people who continued to be sick [20]. VAS was analyzed according to a previously described approach [21]. Adverse effects were measured as incidence of side effects and types of side effects. Quality of life [22] was measured using a validation scale, for example, the Short Form (SF) 36. Symptoms of the dysmenorrhea were analyzed according to a previously described approach [23].

2.3. Search Strategy. We searched PubMed, Cochrane Database of Systematic Reviews, EMBASE, China National Knowledge Infrastructure (CNKI), Wanfang, Chinese Science and Technology Periodical Database (VIP), and sinoMed from inception to May 29, 2019. The following key search terms and their potential combination were used: "Acupuncture Analgesia", "Acupuncture”, "Acupuncture Therapy”, "Acupuncture Points", "moxibustion", "primary dysmenorrhea", "dysmenorrhea", "systematic review", and "meta-analysis". Search strategies are shown in Table 1 or at the following link: http://www.crd.york.ac. uk/PROSPEROFILES/16795_STRATEGY_20150116.pdf.

2.4. Study Selection and Data Extraction. Two reviewers (JY and TY) separately searched the aforementioned databases and listed the titles of all articles. According to the inclusion criteria, by looking through the title and abstract, they excluded papers that were not eligible. Next, they screened the contents of the unclear articles further. If articles contained insufficient information to make a decision on eligibility, authors of the original reports were contacted so as to obtain further details. Finally, investigators (TY and XW) independently extracted data on the first author's name, year, studies/participants, intervention, comparison, main outcomes, and adverse effects from the full text, all of which were recorded by WPS 2019. Any disagreements were resolved by discussion or consulting with a third reviewer $(\mathrm{XJ})$, until reaching a consensus.

2.5. Quality Assessment. On the basis of the first edition (AMSTAR), the newly developed high-quality evaluation tool of systematic review methodology (AMSTAR 2) has 
TABLe 1: Search strategy (PubMed).

\begin{tabular}{|c|c|}
\hline Order & Strategy \\
\hline$\# 1$ & Search "dysmenorrhea"[Mesh] \\
\hline \#2 & Search (((primary dysmenorrhea[Title/Abstract]) OR PD[Title/Abstract]) OR dysmenorrhea[Title/Abstract]) \\
\hline$\# 3$ & $\# 1$ OR \#2 \\
\hline$\# 4$ & $\begin{array}{l}\text { Search “Acupuncture"[Mesh] OR “Acupuncture Therapy”[Mesh] OR “Acupuncture, Ear”[Mesh] OR “Acupuncture } \\
\text { Points”[Mesh] OR “Acupuncture Analgesia”[Mesh] OR "moxibustion”[Mesh] }\end{array}$ \\
\hline$\# 5$ & $\begin{array}{l}\text { Search }(((((\text { Acupuncture[Title/Abstract]) OR Acupuncture Therapy[Title/Abstract]) OR Acupuncture, Ear[Title/Abstract]) } \\
\text { OR Acupuncture Points[Title/Abstract]) OR acupoint[Title/Abstract]) OR electropuncture[Title/Abstract] OR } \\
\text { "moxibustion”[Title/Abstract]) }\end{array}$ \\
\hline \#6 & \#4 OR \#5 \\
\hline \#7 & Search "Systematic Reviews as Topic"[Mesh] OR "Systematic Review"[Publication Type] \\
\hline$\# 8$ & $\begin{array}{c}\text { Search }((((\text { Systematic Reviews[Title/Abstract]) OR Systematic Review[Title/Abstract] }) \text { OR SR[Title/Abstract]) OR SRs[Title/ } \\
\text { Abstract]) OR Review[Title/Abstract] })\end{array}$ \\
\hline$\# 9$ & Search (systematic[Title/Abstract]) AND review[Title/Abstract] \\
\hline$\# 10$ & Search "Meta-Analysis"[Publication Type] OR "Meta-Analysis as Topic"[Mesh] \\
\hline \#11 & Search ((Meta-Analysis[Title/Abstract]) OR meta-analysis[Title/Abstract]) OR meta-analy*[Title/Abstract] \\
\hline \#12 & \#7 OR \#8 OR \#9 OR \#10 OR \#11 \\
\hline \#13 & \#3 AND \#6 AND \#12 \\
\hline
\end{tabular}

good consistency and practicability for estimators. We integrated the preferred reporting items for systematic reviews and Meta-Analyses-Abstract (PRISMA-A) and PRISMA to evaluate the reporting quality of the studies. The methodological quality and reporting quality of the included reviews were respectively assessed by AMSTAR2 and PRISMA.

The investigators systematically studied the relevant data and known evaluation methods. Two reviewers (YJ and YT) independently assessed the quality of the research; disagreements were solved by discussion or consulting with a third reviewer (JX). We calculated the number and 95\% confidence intervals of 3 levels ("Yes," "No," or "Partial Yes") for the AMSTAR-2 and PRISMA items. The 3 levels were scored as $1,0.5$, or 0 points separately for statistical analysis purposes. The methodological quality of each study was evaluated using the system evaluation credibility rating of AMSTAR 2.

2.6. Quality of Evidence. The GRADE approach was used to assess the quality of evidence for main outcomes. The rating included four levels: high, moderate, low, and very low, according to the quality of the evidence. Two reviewers (TY and XW) separately conducted the assessment process, any disagreement was resolved through discussion and consultation with a third author (JX) until a consensus was reached. An overview table, similar to a "summary of findings" table, was prepared with the help of GRADEPro software as per the GRADE approach. The summary table of the evidence for different SRs and MAs was prepared.

2.7. Strategy for Data Synthesis. We performed a re-metaanalysis of the data where two or more reviews reported on the same or similar intervention for outcomes relevant to our review. Given the overlap of some of SRs and MAs, two reviewers listed RCTs of each SRs and MAs and then excluded those that were overlapping. Risk indices
(RRs) or odds ratios (ORs) were standardized for dichotomous outcomes; mean difference (MD) or standard mean difference (SMD) was used for continuous outcomes by using equations published in the Cochrane Handbook for Systematic Reviews of Interventions. RevMan5.3.5 software was used to calculate the standardized effect. According to the heterogeneity levels of the included SRs and meta-analyses, the random-effects model $\left(I^{2} \geq 50 \%\right)$ or fixed-effects model $\left(I^{2}<50 \%\right)$ was properly selected.

\section{Results}

3.1. Results on Literature Search and Selection. We obtained 115 relevant citations from seven electronic databases and manual searches. Before screening, 62 duplicates were excluded. After reading the title and abstract, seven records were rejected, including one article that has been published two times, three papers published in different languages, two conference papers, and 2 network metaanalyses. Full texts of the remaining 39 citations were retrieved for further assessment, and 18 citations were eliminated. Finally, 28 articles were included in this study. Exclusion list is described in additional file 1 . The flowchart of literature selection is represented in Figure 1.

3.2. Characteristics of Included Reviews. Our analysis generated a total of 28 SRs and MAs, 281 original RCT or QRCT (Quasi-Randomized Controlled Trials) studies, including 26,459 patients of PD, published from 2009 to 2019. 12 [15.24.25.31.32.35.37.39.40.42.43.48] studies examined the effect of acupuncture and moxibustion, 3 [13.34.47] the effect of acupressure, 10 [14.26-30.33.36.38.41] the effect of moxibustion, 1 [24] electroacupuncture, 1 [15] acupressure/ acupuncture and moxibustion, and 1 [25] acupressure/ moxibustion.

Among these, 12 [15.24.26.30.31.36.39.41.42.43.47.48] reviews reported adverse effects; 16 reviews 


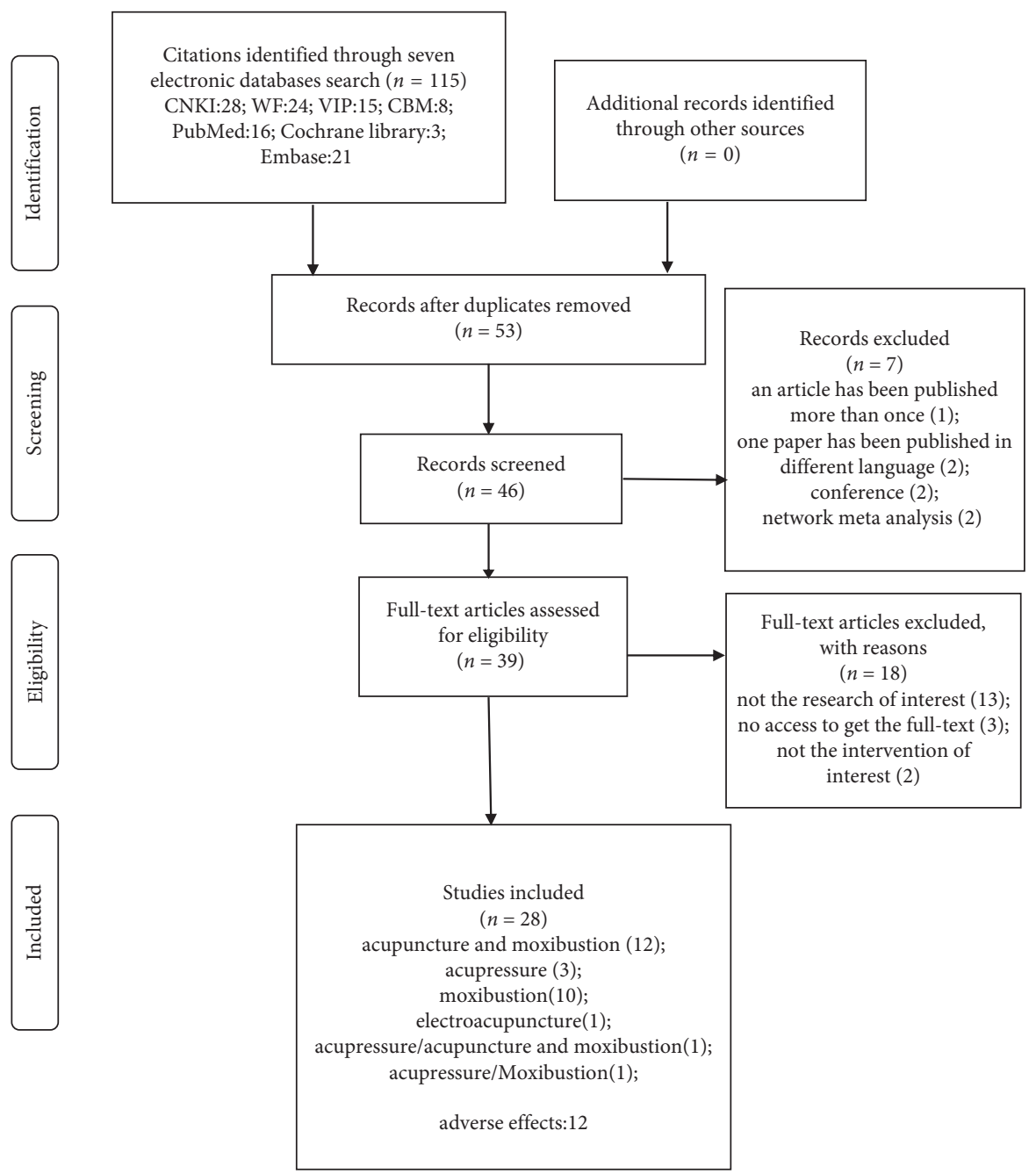

FIGURE 1: Flowchart of literature selection.

[13.14.15.25.26.29.31-33.36.38.40.44-46.48] and 10 reviews [24.27.28.34.35.37.39.42.43.47] applied Cochrane Handbook for Systematic Reviews of Interventions, Version 5.1.0, and Jadad scale for methodological quality assessment of original studies, respectively; and two reviews adopted double method to assess the treatment effect. As for main outcomes, 17 [13.14.24.25.27.28.30.33-38.40.41.46.47] took total effective rate as primary outcomes, 3 studies [26.29.39] payed more attention to clinical effective rate, 9 reviews [13.28.30.33.34.36.39.40.42] focused on VAS, and 12 studies [14.15.24.26.30.31.36.39.41.42.43.47] reported adverse effects. The characteristics of the literature search are shown in Table 2 .

3.3. Methodological Assessment. We adopted AMSTAR 2 to assess the methodological quality of included studies (Table 3; additional file 2). The mean score was 8.8, ranging from 6 to 14 . AMSTAR-2 score showed that the key factors affecting the quality of the literature included item 2 (2 studies explained their review methods before conducting the review), item 4 (1 study provided an comprehensive literature search strategy), item 7 (4 studies provided a list of excluded studies and justified the exclusions), item 9 (19 studies used a satisfactory technique for assessing RoB), item 11 (24 researches applied meta-analytical methods appropriately and gave explaining reasons; 2 studies did not provide the explanation of the heterogeneity), item 13 (25 studies accounted for RoB in individual studies in the results), and item 15 (22 studies took funnel plots or Egger's test and Begger's test to investigate the publication bias, and 9 of the studies gave explanation to discuss the potential impact on the results of the review).

Considering that the common problem of the included studies was lack of protocol and list of excluded studies, we adjusted the items 2 and 7 as the second line of the key factors in the process of the assessment. Our results revealed that more than half of the studies were graded as of critically low quality, 9 of low, 3 of moderate, and 1 of high quality.

Based on the quality results, most reviews followed the principle of PICO to carry on research and build framework. More than 2 reviewers performed study selection and extraction in duplicate. Reviewers evaluated the risk of bias 
TABle 2: Characteristics of the literature search.

\begin{tabular}{|c|c|c|c|c|c|c|}
\hline Review & $\begin{array}{c}\text { Studies } \\
\text { (participants) }\end{array}$ & Intervention & Comparison & Main outcomes & $\begin{array}{c}\text { Risk } \\
\text { assessment } \\
\text { tool }\end{array}$ & $\begin{array}{c}\text { Adverse } \\
\text { effect }\end{array}$ \\
\hline $\begin{array}{l}\text { Fan } \\
{[26]}\end{array}$ & $14(1320)$ & Acupuncture and moxibustion & $\begin{array}{l}\text { Western medicine/ } \\
\text { Chinese medicine }\end{array}$ & $\begin{array}{l}\text { Total effective rate, } \\
\text { VAS, adverse effects }\end{array}$ & Jadad & $\mathrm{Y}$ \\
\hline $\begin{array}{l}\text { Lan et al. } \\
\text { [27] }\end{array}$ & $7(822)$ & $\begin{array}{c}\text { Acupuncture and moxibustion/ } \\
\text { Acupuncture and } \\
\text { moxibustion + others }\end{array}$ & $\begin{array}{l}\text { Placebo acupuncture/ } \\
\text { Western medicine/blank }\end{array}$ & Total effective rate & RoB & $\mathrm{N}$ \\
\hline $\begin{array}{l}\text { Chen et al. } \\
\text { [28] }\end{array}$ & $14(1320)$ & Heat-sensitive moxibustion & No limit & Clinical effective rate & RoB & $\mathrm{Y}$ \\
\hline $\begin{array}{l}\text { Xu et al. } \\
{[29]}\end{array}$ & $15(1261)$ & $\begin{array}{c}\text { Moxibustion/ } \\
\text { Moxibustion + others }\end{array}$ & Not moxibustion & Total effective rate & Jadad & $\mathrm{N}$ \\
\hline $\begin{array}{l}\text { Wang } \\
\text { et al. [30] }\end{array}$ & $12(957)$ & $\begin{array}{l}\text { Heat sensitive moxibustion/ } \\
\text { Heat sensitive } \\
\text { moxibustion }+ \text { others }\end{array}$ & No limit & $\begin{array}{l}\text { Total effective rate, } \\
\text { symptom score of the } \\
\text { dysmenorrhea }\end{array}$ & Jadad & $\mathrm{N}$ \\
\hline $\begin{array}{l}\text { Zhou et al. } \\
\text { [31] }\end{array}$ & $7(542)$ & Heat sensitive moxibustion & No limit & $\begin{array}{l}\text { Clinical effective rate, } \\
\text { cure rate, CMSS }\end{array}$ & RoB & $\mathrm{N}$ \\
\hline $\begin{array}{l}\text { Lu et al. } \\
\text { [32] }\end{array}$ & $13(1524)$ & Indirect moxibustion & $\begin{array}{l}\text { Western medicine/ } \\
\text { Chinese medicine }\end{array}$ & $\begin{array}{l}\text { Total effective rate, } \\
\text { symptom of the } \\
\text { dysmenorrhea, } \\
\text { adverse effects }\end{array}$ & Jadad, RoB & $\mathrm{Y}$ \\
\hline $\begin{array}{l}\text { Woo et al. } \\
{[33]}\end{array}$ & $60(5901)$ & Acupuncture and moxibustion & $\begin{array}{l}\text { Western medicine/sham } \\
\text { acupuncture/blank }\end{array}$ & $\begin{array}{c}\text { Pain intensity, pain } \\
\text { relief、SF-36 }\end{array}$ & RoB & Y \\
\hline $\begin{array}{l}\text { Tong et al. } \\
\text { [34] }\end{array}$ & $23(2770)$ & Acupuncture and moxibustion & Sham acupuncture & VAS, VRS, NRS & RoB & $\mathrm{N}$ \\
\hline $\begin{array}{l}\text { Fan et al. } \\
\text { [35] }\end{array}$ & $13(1040)$ & Warm needling method & $\begin{array}{l}\text { Western medicine/ } \\
\text { Chinese medicine }\end{array}$ & $\begin{array}{l}\text { Total effective rate, } \\
\text { symptom score of the } \\
\text { dysmenorrhea }\end{array}$ & RoB & $\mathrm{N}$ \\
\hline $\begin{array}{l}\text { Sun et al. } \\
{[36]}\end{array}$ & $8(644)$ & $\begin{array}{c}\text { Acupressure/ } \\
\text { acupressure + others }\end{array}$ & Acupuncture + others & $\begin{array}{l}\text { Symptom score of the } \\
\text { dysmenorrhea, total } \\
\text { effective rate, VAS }\end{array}$ & Jadad & $\mathrm{N}$ \\
\hline $\begin{array}{l}\text { Qin et al. } \\
{[37]}\end{array}$ & $19(1760)$ & Acupuncture and moxibustion & $\begin{array}{l}\text { Western medicine/ } \\
\text { Chinese medicine }\end{array}$ & Total effective rate & Jadad & $\mathrm{N}$ \\
\hline Gou [38] & $10(586)$ & Moxibustion & Not moxibustion & $\begin{array}{l}\text { Total effective rate, } \\
\text { symptom of the } \\
\text { dysmenorrhea }\end{array}$ & RoB & $\mathrm{Y}$ \\
\hline $\begin{array}{l}\text { Liu et al. } \\
\text { [39] }\end{array}$ & $14(1123)$ & $\begin{array}{c}\text { Acupuncture and moxibustion/ } \\
\text { acupuncture and } \\
\text { moxibustion + Western } \\
\text { medicine/acupuncture and } \\
\text { moxibustion + Chinese } \\
\text { medicine }\end{array}$ & $\begin{array}{l}\text { Western medicine/ } \\
\text { Chinese medicine }\end{array}$ & Total effective rate & Jadad & $\mathrm{N}$ \\
\hline $\begin{array}{l}\text { Gou et al. } \\
{[40]}\end{array}$ & $12(786)$ & Moxibustion & Not moxibustion & $\begin{array}{l}\text { Total effective rate } \\
\text { pain }\end{array}$ & RoB & $\mathrm{Y}$ \\
\hline Wang [12] & $12(1236)$ & Indirect moxibustion & $\begin{array}{l}\text { Western medicine/ } \\
\text { Chinese medicine }\end{array}$ & Total effective rate & RoB & $\mathrm{N}$ \\
\hline $\begin{array}{l}\text { Lin et al. } \\
{[41]}\end{array}$ & $15(1594)$ & Acupuncture and moxibustion & $\begin{array}{l}\text { Western medicine/ } \\
\text { Chinese medicine }\end{array}$ & $\begin{array}{l}\text { Clinical effective rate, } \\
\text { symptom score of } \\
\text { the dysmenorrhea }\end{array}$ & Jadad & $\mathrm{N}$ \\
\hline $\begin{array}{l}\text { Qin et al. } \\
{[42]}\end{array}$ & $20(2134)$ & Acupuncture and moxibustion & $\begin{array}{l}\text { Western medicine/ } \\
\text { Chinese medicine }\end{array}$ & $\begin{array}{l}\text { Total effective rate, } \\
\text { symptom score of the } \\
\text { dysmenorrhea }\end{array}$ & RoB & $\mathrm{N}$ \\
\hline Listijo [43] & $11(412)$ & Moxibustion & $\begin{array}{l}\text { Western medicine/ } \\
\text { Chinese medicine/ } \\
\text { acupuncture }\end{array}$ & Total effective rate & Jadad, RoB & $\mathrm{Y}$ \\
\hline $\begin{array}{l}\text { Chen et al. } \\
\text { [44] }\end{array}$ & $28(2787)$ & $\begin{array}{c}\text { Acupuncture and moxibustion/ } \\
\text { Acupuncture and } \\
\text { Moxibustion + others }\end{array}$ & $\begin{array}{l}\text { Western medicine/ } \\
\text { Chinese medicine }\end{array}$ & $\begin{array}{l}\text { Total effective rate, } \\
\text { symptom score of the } \\
\text { dysmenorrhea }\end{array}$ & Jadad & $\mathrm{Y}$ \\
\hline
\end{tabular}


TABLE 2: Continued.

\begin{tabular}{|c|c|c|c|c|c|c|}
\hline Review & $\begin{array}{c}\text { Studies } \\
\text { (participants) }\end{array}$ & Intervention & Comparison & Main outcomes & $\begin{array}{l}\text { Risk } \\
\text { assessment } \\
\text { tool }\end{array}$ & $\begin{array}{c}\text { Adverse } \\
\text { effect }\end{array}$ \\
\hline Yang [45] & $32(3910)$ & Acupuncture and moxibustion & $\begin{array}{c}\text { No treatment/placebo/ } \\
\text { acupressure/Western } \\
\text { medicine/Chinese } \\
\text { medicine }\end{array}$ & VAS & Jadad & $\mathrm{Y}$ \\
\hline $\begin{array}{l}\text { Chen et al. } \\
{[46]}\end{array}$ & $8(589)$ & $\begin{array}{l}\text { Acupressure/Acupuncture and } \\
\text { moxibustion }\end{array}$ & $\begin{array}{l}\text { Acupuncture/sham } \\
\text { acupuncture }\end{array}$ & VAS & RoB & $\mathrm{N}$ \\
\hline $\begin{array}{l}\text { Yu et al. } \\
{[24]}\end{array}$ & 9 (3118) & Electroacupuncture & $\begin{array}{l}\text { Pharmacological } \\
\text { treatment/nonacupoints/ } \\
\text { waiting-list groups }\end{array}$ & VAS, RSS & RoB & $\mathrm{N}$ \\
\hline $\begin{array}{l}\mathrm{Xu} \text { et al. } \\
{[11]}\end{array}$ & $16(1679)$ & Acupoint-stimulation & NSAIDs & $\begin{array}{l}\text { Total effective rate, } \\
\text { symptom score of the } \\
\text { dysmenorrhea }\end{array}$ & RoB & $\mathrm{N}$ \\
\hline $\begin{array}{l}\text { Smith et al. } \\
\text { [15] }\end{array}$ & $42(4640)$ & $\begin{array}{l}\text { Acupressure/Acupuncture and } \\
\text { moxibustion }\end{array}$ & NSAIDs/placebo/blank & VAS & RoB & $\mathrm{Y}$ \\
\hline $\begin{array}{l}\text { Xu et al. } \\
{[25]}\end{array}$ & $20(2134)$ & Acupressure/moxibustion & $\begin{array}{l}\text { Not acupuncture and } \\
\text { moxibustion }\end{array}$ & $\begin{array}{l}\text { Total effective rate, } \\
\text { pain intensity }\end{array}$ & RoB & $\mathrm{N}$ \\
\hline $\begin{array}{l}\text { Chung } \\
\text { et al. [47] }\end{array}$ & $25(3109)$ & Acupoint stimulation & No limit & $\begin{array}{l}\text { Total effective rate, } \\
\text { adverse effects }\end{array}$ & Jadad & $\mathrm{Y}$ \\
\hline $\begin{array}{l}\text { Cho and } \\
\text { Hwang } \\
{[48]}\end{array}$ & $27(2806)$ & Acupuncture & No limit & Pain relief & RoB & $\mathrm{Y}$ \\
\hline
\end{tabular}

Y: yes; N: no.

of the included and providing satisfactory explanation for the results, while less attention was paid to the protocol and explanation for selection design, exclusion, or heterogeneity.

3.4. Reporting Quality. PRISMA and PRISMA-A were used to assess the reporting quality of studies (Table 4; additional file 3 ). The mean score was 28.45 , ranging from 21.5 to 33 . We found that most included reviews were of high reporting quality, with the part of the title, information sources, data collection process, risk of bias, and conclusion all being well reported. Some of the weaknesses of the reporting included lack to provide proper report in included studies, synthesis of the results, funding, and registration. In the method section, more than half of the studies provided search strategy for one database, while only one study provided a comprehensive literature search strategy. Thirteen studies did not make additional analysis, and twelve reviews did not refer to the funding.

\subsection{Effectiveness of Acupuncture and Moxibustion}

\subsubsection{Total Effective Rate}

(1) Acupuncture and Moxibustion vs. Indomethacin/Ibuprofen/Fenbid/Somiton. Sixteen SRs [13.14.15.24.25.26.28.30.33. 37.39.40.42.43.45.48] encompassing 22 RCTs (1989 participants) suggested that a combination of acupuncture and moxibustion was superior to indomethacin in treating PD $(\mathrm{OR}=3.9,95 \%$ CI $(2.56,5.95 ; P<0.00001$; Figure 2$)$.
Furthermore, 17 SRs [14.15.25-30.35.37.39.40-43.45.46], including 29 RCTs (2995 participants), suggested that a combination of acupuncture and moxibustion was more effective than ibuprofen for treatment of $\mathrm{PD}(\mathrm{OR}=3.55,95 \%$ CI $(2.98,4.39)$; $P<0.00001$; Figure 3). Moreover, 12 SRs encompassing [13.15.24.35.37-40.42.43.45.46] 13 RCTs (909 participants) showed that acupuncture and moxibustion were superior to Fenbid ( $\mathrm{OR}=7.68,95 \% \mathrm{CI}(4.98,11.86)$; $P<0.00001$; Figure 4). Also, 5 SRs [14.25.40.42.43] covering 9 RCTs (983 participants) showed that acupuncture and moxibustion were superior to Somiton in treatment of PD patients $(\mathrm{OR}=2.17,95 \%$ CI $(1.56,3.02) ; \quad P<0.00001$; Figure 5).

\subsubsection{VAS}

(1) Acupuncture and Moxibustion vs. NSAIDs/Sham Acupuncture/No Treatment. Seven SRs [13.15.22.32.43.47.48] encompassing 17 RCTs (1138 participants) suggested that a combination of acupuncture and moxibustion was superior to NSAIDs in relieving pain $(\mathrm{MD}=-1.96,95 \% \mathrm{CI}$ $(-2.76,-1.17) ; P<0.00001$; Figure 6). In addition, 5 SRs [15.31.32.44.45] encompassing 16 RCTs (2653 participants) reported that acupuncture and moxibustion significantly reduced the pain compared with sham acupuncture $\quad(\mathrm{MD}=-4.38,95 \% \quad \mathrm{CI} \quad(-6.15,-2.60)$; $P<0.00001$; Figure 7). Moreover, four SRs [15.31.44.45] encompassing 11 RCTs (667 participants) consistently showed that acupuncture and moxibustion were superior to no treatment in relieving pain $\mathrm{MD}=-5.2195 \% \mathrm{CI}$ (-6.32, -4.10); $P<0.00001$; Figure 8). 
TABLE 3: Methodological quality of the included reviews assessed by AMSTAR2

\begin{tabular}{|c|c|c|c|c|c|c|c|}
\hline \multirow{2}{*}{$\begin{array}{l}\text { Item } \\
\text { no. }\end{array}$} & \multirow{2}{*}{ Checklist item } & \multicolumn{2}{|r|}{$\mathrm{Y}$} & \multicolumn{2}{|c|}{ PY } & \multicolumn{2}{|c|}{$\mathrm{N}$} \\
\hline & & $n(\%)$ & $95 \% \mathrm{CI}$ & $n(\%)$ & $95 \% \mathrm{CI}$ & $n(\%)$ & $95 \% \mathrm{CI}$ \\
\hline 1 & $\begin{array}{l}\text { Did the research questions and inclusion criteria for the review } \\
\text { include the components of PICO (population, intervention, } \\
\text { control group, and outcome)? }\end{array}$ & $\begin{array}{c}27 \\
(96.43)\end{array}$ & {$[0.89,1.03]$} & 0 & & $1(3.57)$ & $\begin{array}{c}{[-0.03,} \\
0.10]\end{array}$ \\
\hline 2 & $\begin{array}{l}\text { Did the report of the review contain an explicit statement that } \\
\text { the review methods were established prior to the conduct of } \\
\text { the review and did the report justify any significant deviations } \\
\text { from the protocol? }\end{array}$ & $2(7.14)$ & {$[-0.02,0.17]$} & 0 & & $\begin{array}{c}26 \\
(92.86)\end{array}$ & $\begin{array}{l}{[0.83} \\
1.02]\end{array}$ \\
\hline 3 & $\begin{array}{l}\text { Did the review authors explain their selection of the study } \\
\text { designs for inclusion in the review? }\end{array}$ & 0 & & 0 & & $28(100)$ & \\
\hline 4 & $\begin{array}{c}\text { Did the review authors use a comprehensive literature search } \\
\text { strategy? }\end{array}$ & $1(3.57)$ & {$[-0.03,0.10]$} & $\begin{array}{c}27 \\
(96.43)\end{array}$ & $\begin{array}{l}{[0.89} \\
1.03]\end{array}$ & 0 & \\
\hline 5 & Did the review authors perform study selection in duplicate? & $\begin{array}{c}26 \\
(92.86)\end{array}$ & {$[0.83,1.02]$} & 0 & & $2(7.14)$ & $\begin{array}{c}{[-0.02} \\
0.17]\end{array}$ \\
\hline 6 & Did the review authors perform data extraction in duplicate? & $\begin{array}{c}25 \\
(89.29)\end{array}$ & {$[0.78,1.01]$} & 0 & & $\begin{array}{c}3 \\
(10.71)\end{array}$ & $\begin{array}{c}{[-0.01} \\
0.22]\end{array}$ \\
\hline 7 & $\begin{array}{c}\text { Did the review authors provide a list of excluded studies and } \\
\text { justify the exclusions? }\end{array}$ & $\begin{array}{c}4 \\
(14.29)\end{array}$ & {$[0.01,0.27]$} & $1(3.57)$ & $\begin{array}{c}{[-0.03} \\
0.10]\end{array}$ & $(82.14)$ & $\begin{array}{l}{[0.68} \\
0.96]\end{array}$ \\
\hline 8 & $\begin{array}{l}\text { Did the review authors describe the included studies in } \\
\text { adequate detail? }\end{array}$ & $\begin{array}{c}3 \\
(10.71)\end{array}$ & {$[-0.01,0.22]$} & $\begin{array}{c}25 \\
(89.29)\end{array}$ & $\begin{array}{l}{[0.78} \\
1.01]\end{array}$ & 0 & \\
\hline 9 & $\begin{array}{c}\text { Did the review authors use a satisfactory technique for } \\
\text { assessing the risk of bias (RoB) in individual studies that were } \\
\text { included in the review? }\end{array}$ & $\begin{array}{c}19 \\
(67.86)\end{array}$ & {$[0.51,0.85]$} & $\begin{array}{c}9 \\
(32.14)\end{array}$ & $\begin{array}{l}{[0.15,} \\
0.49]\end{array}$ & 0 & \\
\hline 10 & $\begin{array}{l}\text { Did the review authors report on the sources of funding for the } \\
\text { studies included in the review? }\end{array}$ & $\begin{array}{c}15 \\
(53.57)\end{array}$ & {$[0.35,0.72]$} & 0 & & $\begin{array}{c}13 \\
(46.43)\end{array}$ & $\begin{array}{l}{[0.28} \\
0.65]\end{array}$ \\
\hline 11 & $\begin{array}{l}\text { If meta-analysis (MA) was justified did the review authors use } \\
\text { appropriate methods for statistical combination of results? }\end{array}$ & $\begin{array}{c}24 \\
(85.71)\end{array}$ & {$[0.73,0.99]$} & $2(7.14)$ & $\begin{array}{c}{[-0.02} \\
0.17]\end{array}$ & $2(7.14)$ & $\begin{array}{c}{[-0.02} \\
0.17]\end{array}$ \\
\hline 12 & $\begin{array}{l}\text { If meta-analysis was performed did the review authors assess } \\
\text { the potential impact of RoB in individual studies on the results } \\
\text { of the meta-analysis or other evidence synthesis? }\end{array}$ & $\begin{array}{c}4 \\
(14.29)\end{array}$ & {$[0.01,0.27]$} & 0 & & $\begin{array}{c}24 \\
(85.71)\end{array}$ & $\begin{array}{c}{[0.73,} \\
0.99]\end{array}$ \\
\hline 13 & $\begin{array}{l}\text { Did the review authors account for RoB in individual studies } \\
\text { when interpreting/discussing the results of the review? }\end{array}$ & $\begin{array}{c}25 \\
(89.29)\end{array}$ & {$[0.78,1.01]$} & 0 & & $\begin{array}{c}3 \\
(10.71)\end{array}$ & $\begin{array}{c}{[-0.01} \\
0.22]\end{array}$ \\
\hline 14 & $\begin{array}{l}\text { Did the review authors provide a satisfactory explanation for, } \\
\text { and discussion of, any heterogeneity observed in the results of } \\
\text { the review? }\end{array}$ & $\begin{array}{c}23 \\
(82.14)\end{array}$ & {$[0.68,0.96]$} & $1(3.57)$ & $\begin{array}{l}{[-0.03} \\
0.10]\end{array}$ & $\begin{array}{c}5 \\
(17.86)\end{array}$ & $\begin{array}{c}{[0.04} \\
0.32]\end{array}$ \\
\hline 15 & $\begin{array}{l}\text { If they performed quantitative synthesis did the review authors } \\
\text { carry out an adequate investigation of publication bias (small } \\
\text { study bias) and discuss its likely impact on the results of the } \\
\text { review? }\end{array}$ & $\begin{array}{c}9 \\
(32.14)\end{array}$ & {$[0.15,0.49]$} & $\begin{array}{c}13 \\
(46.43)\end{array}$ & $\begin{array}{l}{[0.28} \\
0.65]\end{array}$ & $\begin{array}{c}6 \\
(21.43)\end{array}$ & $\begin{array}{l}{[0.06} \\
0.37]\end{array}$ \\
\hline 16 & $\begin{array}{l}\text { Did the review authors report any potential sources of conflict } \\
\text { of interest, including any funding they received for conducting } \\
\text { the review? }\end{array}$ & $\begin{array}{c}12 \\
(42.86)\end{array}$ & {$[0.25,0.61]$} & $2(7.14)$ & $\begin{array}{c}{[-0.02} \\
0.17]\end{array}$ & $14(50)$ & $\begin{array}{l}{[0,31} \\
0.69]\end{array}$ \\
\hline
\end{tabular}

Y: yes; N: no; P: partial satisfaction.

3.6. Adverse Events. Seven SRs [13.15.24.30.36.38.47] encompassing 8 RCTs (667 participants) consistently showed that acupuncture and moxibustion were safer compared to NSAIDs in treatment of $\mathrm{PD}(\mathrm{OR}=0.17,95 \% \mathrm{CI}$ (0.03, 1.04); $P=0.06$; Figure 9).

3.7. Quality of Evidence. The quality of evidence for 3 outcomes (total effective rate, VAS and adverse events) is shown in Table 5. The results showed that the quality of the evidence was low and all the outcomes were biased in allocation concealment or inadequate blinding; the outcomes of the VAS and adverse events were inconsistent, which was caused by course or treatment of the patient. The funnel plot of the total effective rate (acupuncture and moxibustion vs. indomethacin and acupuncture and moxibustion vs. Somiton) and VAS (acupuncture and moxibustion vs. no treatment) was dissymmetrical.

\section{Discussion}

4.1. Summary of Main Findings. This overview provided a comprehensive overview of the evidence on the effectiveness and safety of acupuncture and moxibustion for PD. Evidence of moderate quality suggested that acupuncture and moxibustion had a positive effect on indomethacin or Fenbid in treating PD. Low-quality evidence showed that compared to NSAIDs, acupuncture and moxibustion could relieve PD related pain with less adverse effects, which needs to be further researched. The adverse effects related to the 
TABLE 4: Reporting quality of the included reviews assessed by PRISMA.

\begin{tabular}{|c|c|c|c|c|c|c|c|}
\hline \multirow{2}{*}{ Item } & \multirow{2}{*}{ Checklist item PRISMA } & \multicolumn{2}{|c|}{$\mathrm{Y}$} & \multicolumn{2}{|c|}{ PY } & \multicolumn{2}{|c|}{$\mathrm{N}$} \\
\hline & & $n(\%)$ & $95 \% \mathrm{CI}$ & $n(\%)$ & $95 \% \mathrm{CI}$ & $n(\%)$ & $95 \% \mathrm{CI}$ \\
\hline \multicolumn{8}{|l|}{ Tiltle } \\
\hline & Title & $27(96.43)$ & {$[0.89,1.03]$} & 0 & & $1(3.57)$ & {$[-0.03,0.10]$} \\
\hline \multicolumn{8}{|c|}{ Abstract } \\
\hline & Objectives & $28(100)$ & & 0 & & 0 & \\
\hline & Eligibility criteria & $28(100)$ & & 0 & & 0 & \\
\hline & Information sources & $27(96.43)$ & {$[0.89,1.03]$} & 0 & & $1(3.57)$ & {$[-0.03,0.10]$} \\
\hline & Risk of bias & $7(25)$ & {$[0.09,0.41]$} & 0 & & $21(75)$ & {$[0.59,0.91]$} \\
\hline & Included studies & $23(82.14)$ & {$[0.68,0.96]$} & 0 & & $5(17.86)$ & {$[0.04,0.32]$} \\
\hline & Synthesis of results & $2(7.14)$ & {$[-0.02,0.17]$} & $18(64.29)$ & {$[0.47,0.82]$} & $8(28.57)$ & {$[0.12,0.45]$} \\
\hline & Description of the effect & $19(67.86)$ & {$[0.51,0.85]$} & 0 & & $9(32.14)$ & {$[0.15,0.49]$} \\
\hline & Strengths and limitations of evidence & $22(78.57)$ & {$[0.63,0.94]$} & 0 & & $6(21.43)$ & {$[0.06,0.37]$} \\
\hline & Interpretation & $28(100)$ & & 0 & & 0 & \\
\hline & Funding & 0 & & 0 & & $28(100)$ & \\
\hline & Registration & $1(3.57)$ & {$[-0.03,0.10]$} & 0 & & $27(96.43)$ & {$[0.89,1.03]$} \\
\hline \multicolumn{8}{|c|}{ Introduction } \\
\hline & Rationale & $27(96.43)$ & {$[0.89,1.03]$} & 0 & & $1(3.57)$ & {$[-0.03,0.10]$} \\
\hline & Objectives & $28(100)$ & & 0 & & 0 & \\
\hline \multicolumn{8}{|c|}{ Methods } \\
\hline & Protocol and registration & $4(14.29)$ & {$[0.01,0.27]$} & 0 & & $24(85.71)$ & {$[0.73,0.99]$} \\
\hline & Eligibility criteria & $27(96.43)$ & {$[0.89,1.03]$} & $1(3.57)$ & {$[-0.03,0.10]$} & 0 & \\
\hline & Information sources & $28(100)$ & & 0 & & 0 & \\
\hline & Search & $7(25)$ & {$[0.09,0.41]$} & $21(75)$ & {$[0.59,0.91]$} & & \\
\hline & Study selection & $24(85.71)$ & {$[0.73,0.99]$} & $2(7.14)$ & {$[-0.02,0.17]$} & $2(7.14)$ & {$[-0.02,0.17]$} \\
\hline & Data collection process & $25(89.29)$ & {$[0.78,1.01]$} & $1(3.57)$ & {$[-0.03,0.10]$} & $2(7.14)$ & {$[-0.02,0.17]$} \\
\hline & Data items & $19(67.86)$ & {$[0.51,0.85]$} & $2(7.14)$ & {$[-0.02,0.17]$} & $7(25)$ & {$[0.09,0.41]$} \\
\hline & Risk of bias in individual studies & $13(46.43)$ & {$[0.28,0.65]$} & $15(53.57)$ & {$[0.35,0.72]$} & 0 & \\
\hline & Summary measures & $28(100)$ & & & & & \\
\hline & Synthesis of results & $25(89.29)$ & {$[0.78,1.01]$} & 0 & & $3(10.71)$ & {$[-0.01,0.22]$} \\
\hline & Risk of bias across studies & $21(75)$ & {$[0.59,0.91]$} & $4(14.29)$ & {$[0.01,0.27]$} & $3(10.71)$ & {$[-0.01,0.22]$} \\
\hline & Additional analyses & $17(60.71)$ & {$[0.43,0.79]$} & 0 & & $11(39.29)$ & {$[0.21,0.57]$} \\
\hline \multicolumn{8}{|c|}{ Results } \\
\hline & Study selection & $27(96.43)$ & {$[0.89,1.03]$} & 0 & & $1(3.57)$ & {$[-0.03,0.10]$} \\
\hline & Study characteristics & $27(96.43)$ & {$[0.89,1.03]$} & $1(3.57)$ & {$[-0.03,0.10]$} & 0 & \\
\hline & Risk of bias within studies & $27(96.43)$ & {$[0.89,1.03]$} & 0 & & $1(3.57)$ & {$[-0.03,0.10]$} \\
\hline & Results of individual studies & $28(100)$ & & 0 & & 0 & \\
\hline & Synthesis of results & $26(92.86)$ & {$[0.83,1.02]$} & $1(3.57)$ & {$[-0.03,0.10]$} & $1(3.57)$ & {$[-0.03,0.10]$} \\
\hline & Risk of bias across studies & $27(96.43)$ & {$[0.89,1.03]$} & $1(3.57)$ & {$[-0.03,0.10]$} & 0 & \\
\hline & Additional analysis & $15(53.57)$ & {$[0.35,0.72]$} & 0 & & $13(46.43)$ & {$[0.28,0.65]$} \\
\hline Discussion & Summary of evidence & $8(28.57)$ & {$[0.12,0.45]$} & $20(71.43)$ & {$[0.55,0.88]$} & 0 & \\
\hline & Limitations & $26(92.86)$ & {$[0.83,1.02]$} & 0 & & $2(7.14)$ & {$[-0.02,0.17]$} \\
\hline & Conclusions & $26(92.86)$ & {$[0.83,1.02]$} & $1(3.57)$ & {$[-0.03,0.10]$} & $1(3.57)$ & {$[-0.03,0.10]$} \\
\hline Funding & Funding & $10(35.71)$ & {$[0.18,0.53]$} & $6(21.43)$ & {$[0.06,0.37]$} & $12(42.86)$ & {$[0.25,0.61]$} \\
\hline
\end{tabular}

Y: yes; N: no; P: partial satisfaction.

acupuncture and moxibustion were mild, and they included dizziness, fainting, or minimal bleeding after acupuncture.

The majority of the SRs were of moderate reporting quality and poor methodological quality. Most of the studies followed the principle of PICO to carry on research and build framework, select proper assessment tool or appropriate methods for statistical combination of results, while they fail to provide registration, and assess the potential impact of individual ROB studies on the results of the meta-analysis or other evidence synthesis. Most of the RCTs did not explain the treatment allocation concealed and blinding. The quality of the reporting of the SRs was limited by lack of data on registration and funding, comprehensive search strategy, and explanation of the heterogeneity. With reference to the abstract, although many studies reported structured abstract, they failed to fully report the synthesis of results, the risk of basis, funding, and registration.

4.2. Strengths and Limitation. Following is the brief summary of the present research: (1) comprehensive search strategies were applied to seven databases to ensure that all relevant reviews were identified; (2) before assessment, we 


\begin{tabular}{|c|c|c|c|c|c|c|c|c|c|}
\hline \multirow{3}{*}{$\frac{\text { Study or subgroup }}{\text { Bi WL } 2007}$} & \multicolumn{2}{|c|}{ Acupuncture and moxlbustlon } & \multicolumn{2}{|c|}{ Indomethacln } & \multirow{2}{*}{ Weight (\%) } & \multirow{2}{*}{$\begin{array}{c}\text { Odds ratio } \\
\mathrm{M}-\mathrm{H}, \text { random, } 95 \% \mathrm{CI}\end{array}$} & \multirow{2}{*}{\multicolumn{2}{|c|}{$\begin{array}{c}\text { Odds ratio } \\
\mathrm{M}-\mathrm{H} \text {, random, } 95 \% \mathrm{CI}\end{array}$}} & Risk of bias \\
\hline & \multirow{2}{*}{$\begin{array}{c}\text { Events } \\
22\end{array}$} & \multirow{2}{*}{ Total } & \multirow{2}{*}{$\frac{\text { Events }}{6}$} & \multirow{2}{*}{$\frac{\text { Total }}{25}$} & & & & & \multirow{2}{*}{$\begin{array}{l}\text { А В C D E F G } \\
? ? ? ? ?+\bullet \odot ? ?\end{array}$} \\
\hline & & & & & 4.3 & $23.22[5.10,105.73]$ & & \multirow{3}{*}{ 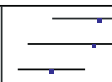 } & \\
\hline Chen LM 2006 & 29 & 30 & 18 & 30 & 2.8 & $19.33[2.31,161.57]$ & & & \multirow{5}{*}{ 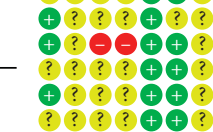 } \\
\hline Chen YL 2009 & 47 & 52 & 34 & 52 & 5.8 & $4.98[1.68,14.72]$ & & & \\
\hline Du LF 2009 & 36 & 36 & 23 & 30 & 1.7 & $23.30[1.27,427.36]$ & & & \\
\hline Ji L 2012 & 29 & 30 & 25 & 30 & 2.6 & $5.80[0.63,53.01]$ & & & \\
\hline Jiang LY 2007 & 33 & 34 & 29 & 34 & 2.6 & $5.69[0.63,51.57]$ & & & \\
\hline LinQ2012 & 76 & 80 & 48 & 60 & 5.4 & $4.75[1.45,15.58]$ & & & †OEOO? \\
\hline Liu C 2011a & 26 & 40 & 13 & 40 & 6.5 & $3.86[1.53,9.75]$ & & 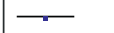 & ? ? ? ? ? ? \\
\hline Rao Y 2009 & 25 & 30 & 18 & 30 & 5.3 & $3.33[1.00,11.14]$ & & & ? ? ? ? $\oplus \oplus$ \\
\hline Tao R 2010 & 41 & 45 & 29 & 41 & 5.3 & $4.24[1.24,14.47]$ & & & ? ? ? ? †? \\
\hline Wang K2005 & 29 & 30 & 18 & 28 & 2.8 & $16.11[1.90,136.68]$ & & & † ? ? ? † ? ? \\
\hline Wu RD 2007 & 60 & 114 & 54 & 114 & 8.3 & $1.23[0.73,2.08]$ & & - & - $\odot$ ? $\oplus$ ? \\
\hline Xing OK 2011 & 55 & 60 & 42 & 54 & 5.7 & $3.14[1.03,9.61]$ & & & ? ? ? ? ? \\
\hline Xing QX 2011 & 55 & 60 & 42 & 54 & 5.7 & $3.14[1.03,9.61]$ & & & \\
\hline Xue HF 2009 & 30 & 30 & 26 & 30 & 1.7 & $10.36[0.53,201.45]$ & & & $?$ \\
\hline Yang M 2009 & 34 & 36 & 29 & 36 & 3.9 & $4.10[0.79,21.32]$ & & & †? ? ? ? ? \\
\hline Zhang LM 2012a & 57 & 61 & 45 & 55 & 5.3 & $3.17[0.93,10.77]$ & & & † ? ? ? † † ? \\
\hline Zhang LM 2012b & 42 & 45 & 32 & 45 & 4.9 & $5.69[1.49,21.66]$ & & & † ? ? ? † ? ? \\
\hline Zhi XL 2007 & 56 & 80 & 45 & 55 & 6.9 & $0.52[0.22,1.20]$ & & & ? ? ? ? $†+$ ? \\
\hline Zhu C 2011 & 19 & 20 & 16 & 20 & 2.5 & $4.75[0.48,46.91]$ & & & †? ? ? †? ? \\
\hline Zhu Y 2010 & 47 & 51 & 39 & 51 & 5.3 & $3.62[1.08,12.11]$ & & & $\uparrow ? ? ?+\oplus$ ? \\
\hline Zhu Y 2011 & 40 & 43 & 33 & 43 & 4.7 & $4.04[1.03,15.90]$ & & & $† ? ? ?+\odot ?$ \\
\hline Total $(95 \%$ CI) & & 1032 & & 957 & 100.0 & $3.90[2.56,5.95]$ & & 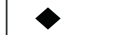 & \\
\hline Total events & 888 & & 664 & & & & & & \\
\hline Heterogeneity: tau $^{2}$ & $\mathrm{chi}^{2}=47.12$ & $21(P=0.0009$ & 9); $I^{2}=55$ & & & 0.002 & 0.1 & 10 & 500 \\
\hline Test for overall effec & $6.32(P<0.000$ & & & & & & hacin & $\begin{array}{l}\text { Acupunct } \\
\text { moxib }\end{array}$ & \\
\hline
\end{tabular}

Risk of bias legend

(A) Random sequence generation (selection bias)

(B) Allocation concealment (selection bias)

(C) Blinding of participants and personnel (performance bias)

(D) Blinding of outcome assessment (detection bias)

(E) Incomplete outcome data (attrition bias)

(F) Selective reporting (reporting bias)

(G) Other bias

Figure 2: Acupuncture and moxibustion vs. indomethacin.

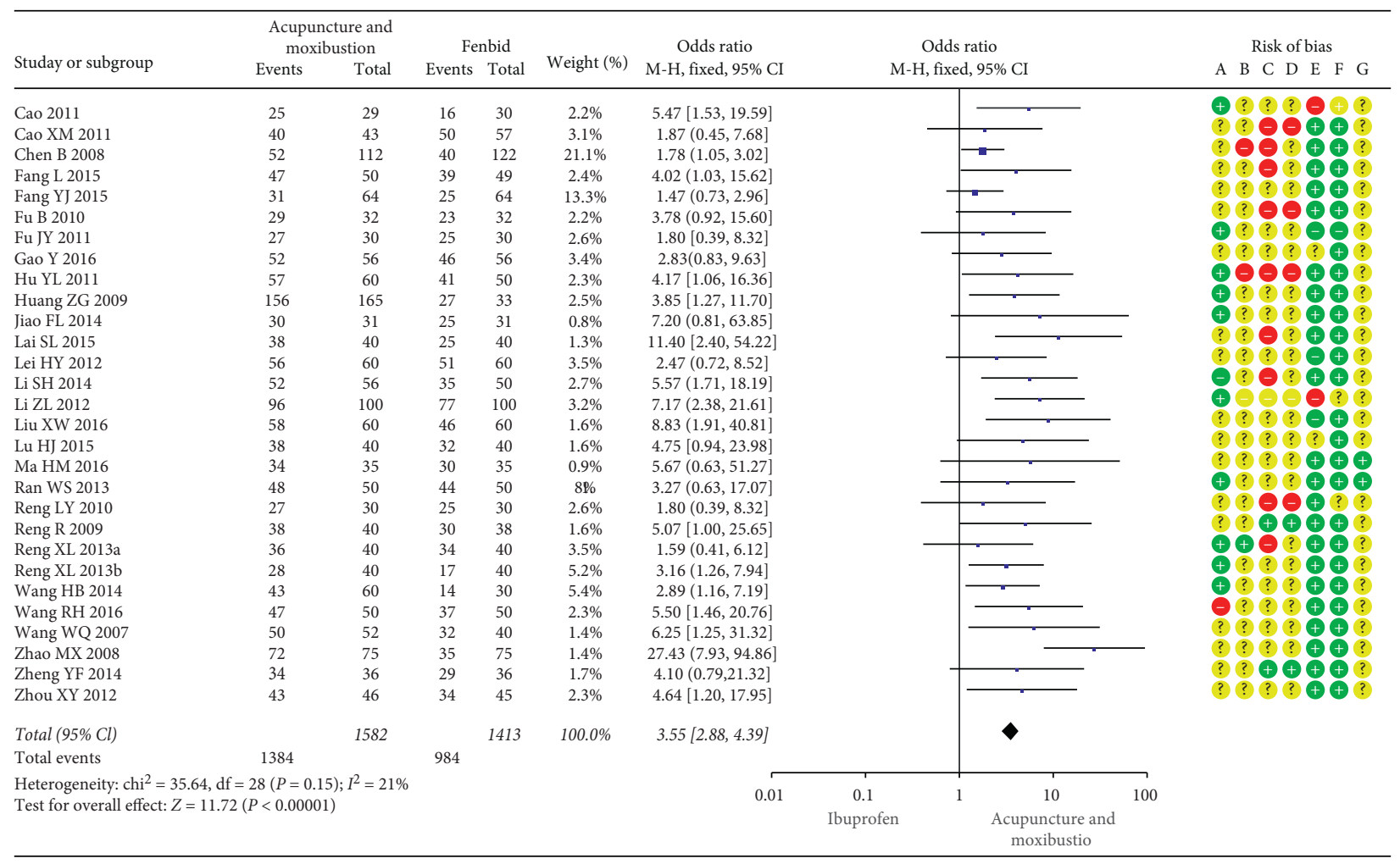

Risk of bias legend

(A) Random sequence generation (selection bias)

(B) Allocation concealment (selection bias)

(C) Blinding of participants and personnel (performance bias)

(D) Blinding of outcome assessment (detection bias)

(E) Incomplete outcome data (attrition bias)

(F) Selective reporting (reporting bias)

(G) Other bias

Figure 3: Acupuncture and moxibustion vs. ibuprofen. 


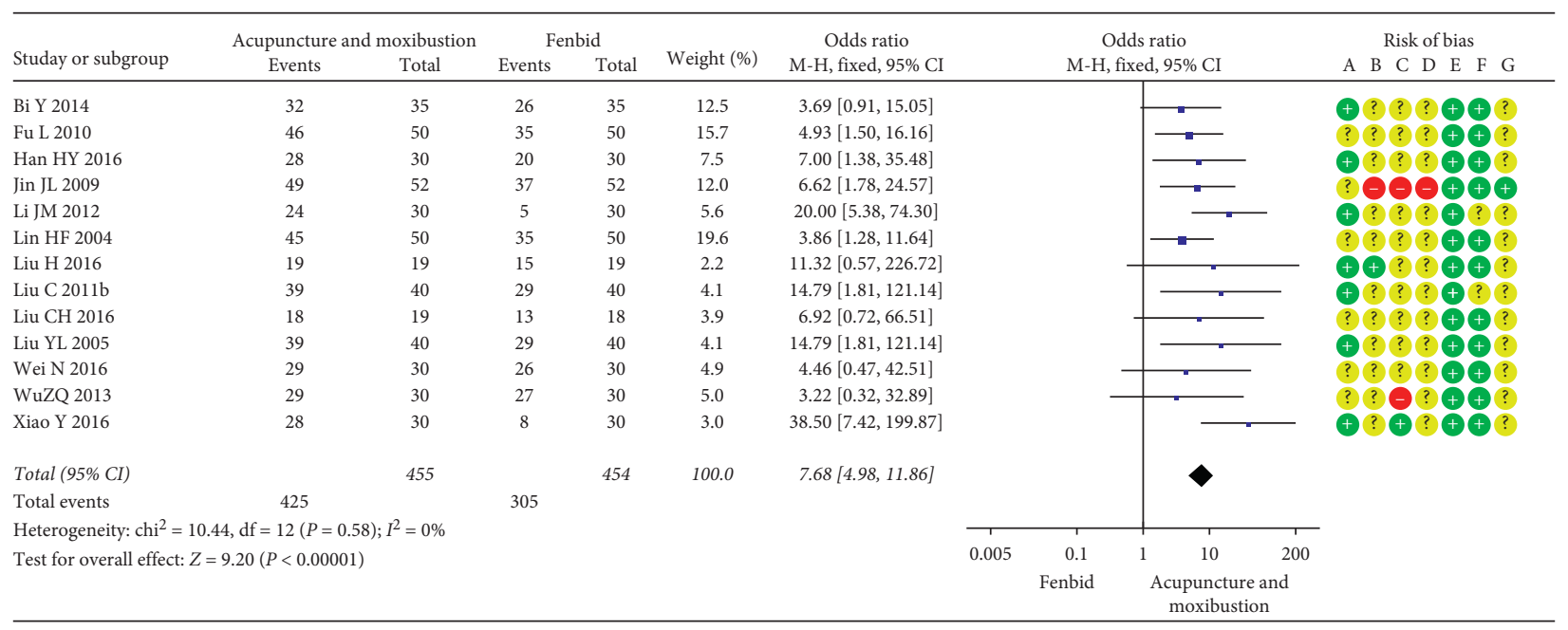

Risk of bias legend

(A) Random sequence generation (selection bias)

(B) Allocation concealment (selection bias)

(C) Blinding of participants and personnel (performance bias)

(D) Blinding of outcome assessment (detection bias)

(E) Incomplete outcome data (attrition bias)

(F) Selective reporting (reporting bias)

(G) Other bias

Figure 4: Acupuncture and moxibustion vs. Fenbid.

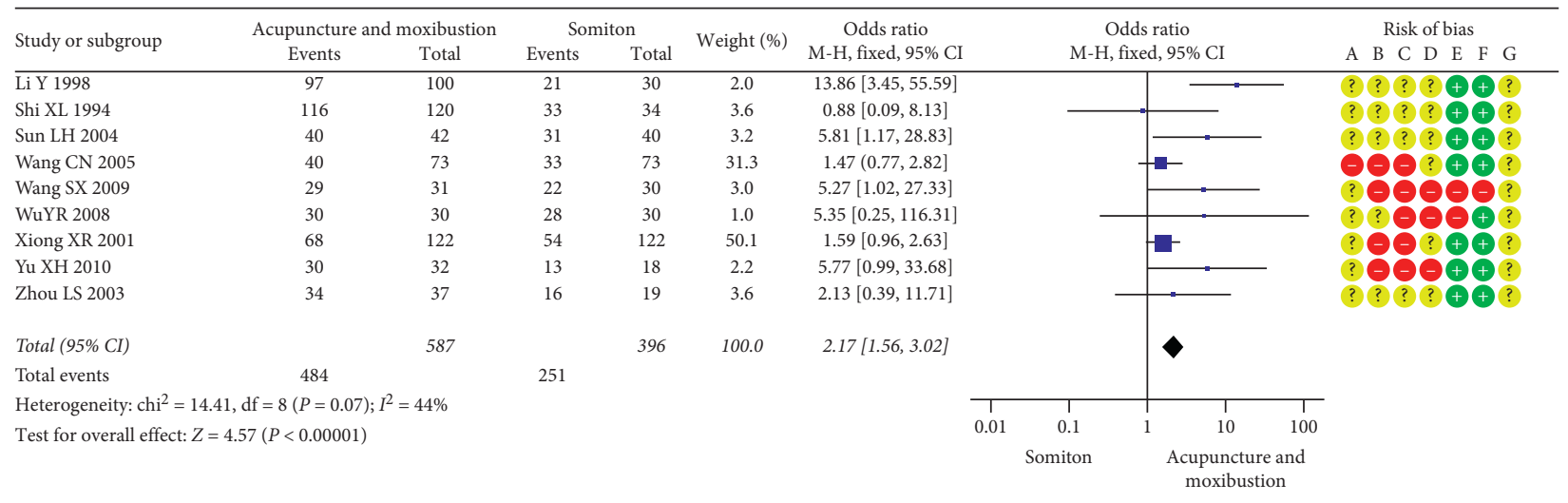

Risk of bias legend

(A) Random sequence generation (selection bias)

(B) Allocation concealment (selection bias)

(C) Blinding of participants and personnel (performance bias)

(D) Blinding of outcome assessment (detection bias)

(E) Incomplete outcome data (attrition bias)

(F) Selective reporting (reporting bias)

(G) Other bias

Figure 5: Acupuncture and moxibustion vs. Somiton.

have systematically learned some related courses on methodology and reporting evaluation and consulted relevant methodological experts, professors so as to gain deep understanding, and ensure the accuracy of the evaluation process; (3) during the process, we adopted AMSTAR 2 and PRISMA to evaluate the methodological and reporting quality of the qualified studies, and we combined PRISMA-A to the part of abstract in PRISMA, thus making the evaluation more precise; (4) we excluded the overlapping RCTs and conducted a quantitative analysis of the primary RCTs, with the help of the GRADE approach so as to evaluate the quality of the outcomes with different comparisons; (5) Cochrane Collaboration guidelines were followed for data synthesis. More than two reviewers were engaged so as to minimize potential bias in the overview process.

There are some limitations in the present study: (1) The methodological quality of both included SRs and primary RCTs was not high, and the quality of evidence for the outcomes was unsatisfactory; thus, the conclusions from this 


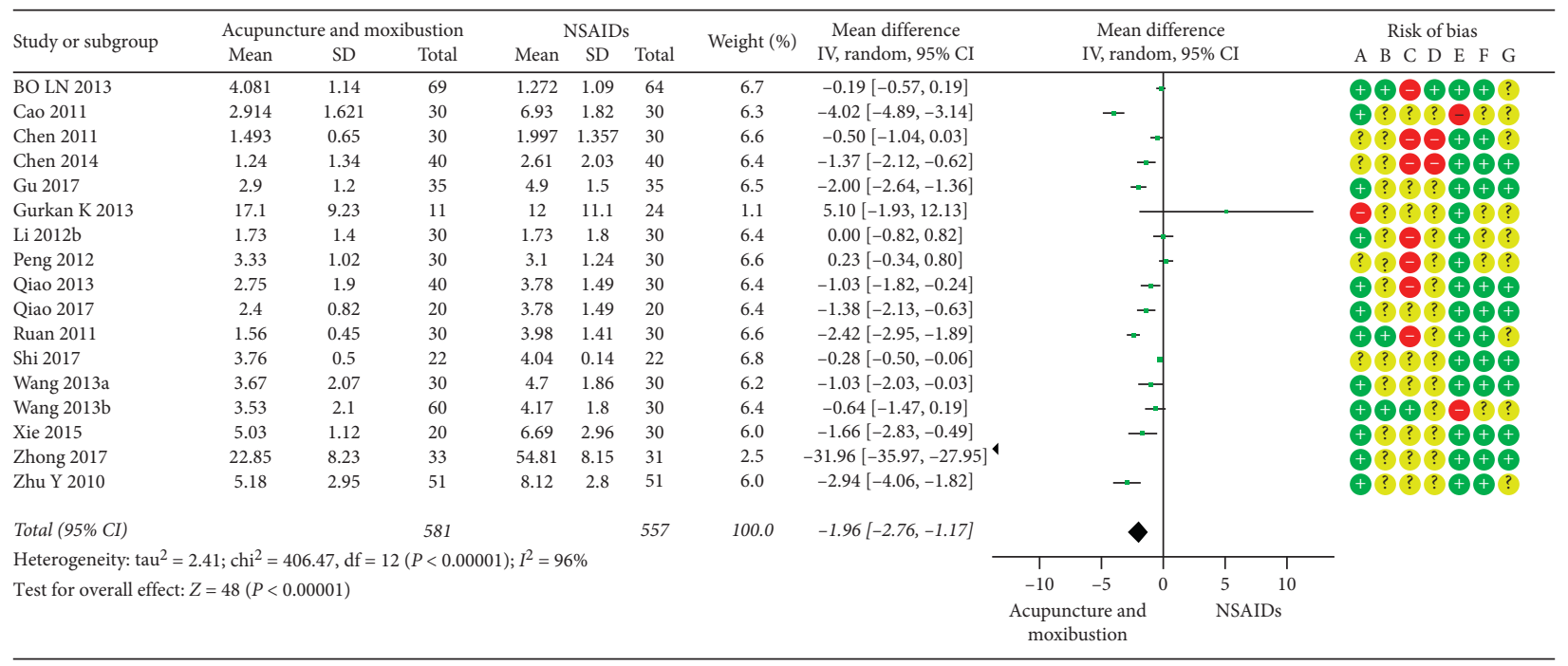

Risk of bias legend

(A) Random sequence generation (selection bias)

(B) Allocation concealment (selection bias)

(C) Blinding of participants and personnel (performance bias)

(D) Blinding of outcome assessment (detection bias)

(E) Incomplete outcome data (attrition bias)

(F) Selective reporting (reporting bias)

(G) Other bias

FIgURE 6: Acupuncture and moxibustion vs. NSAIDs.

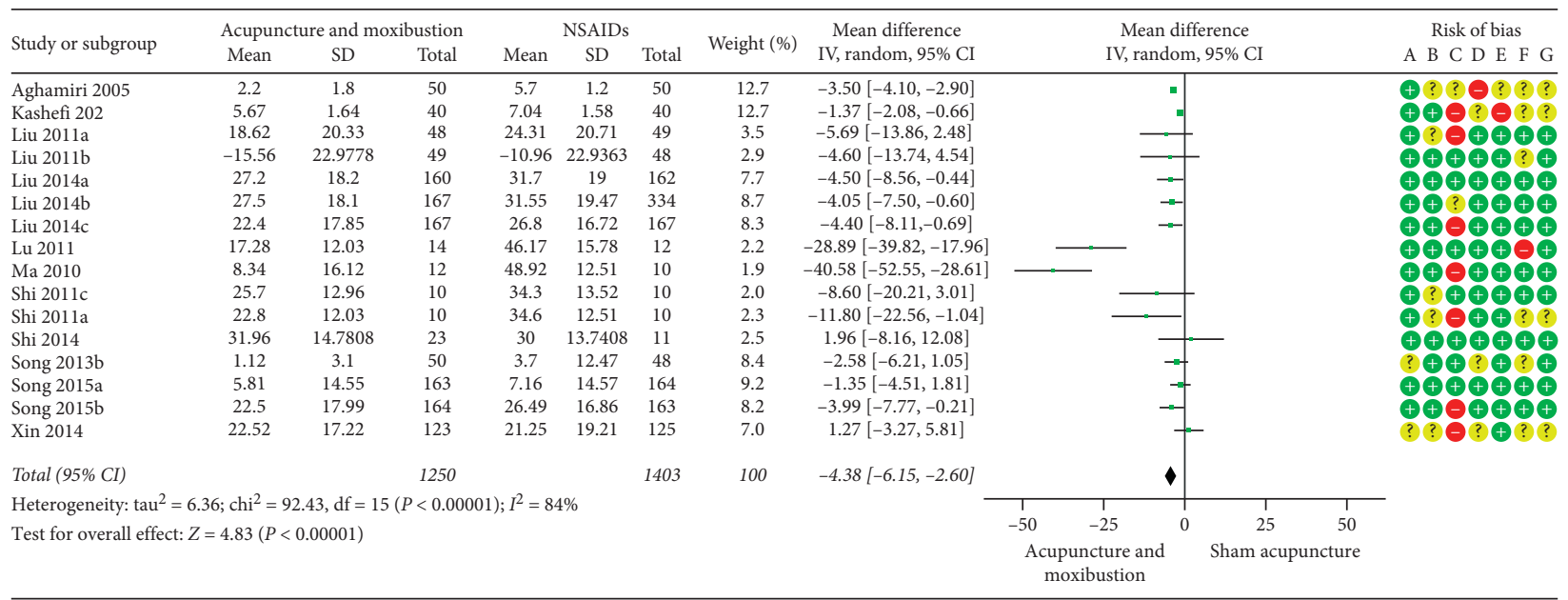

Risk of bias legend

(A) Random sequence generation (selection bias)

(B) Allocation concealment (selection bias)

(C) Blinding of participants and personnel (performance bias)

(D) Blinding of outcome assessment (detection bias)

(E) Incomplete outcome data (attrition bias)

(F) Selective reporting (reporting bias)

(G) Other bias

FIgURE 7: Acupuncture and moxibustion vs. sham acupuncture.

overview should be interpreted with caution. (2) The current overview was constrained by limitations of the included SRs. During the process of literature selection, some SRs and MAs included Q-RCT (quasi-randomized controlled trials). The increase of complex factors led to less reliance in our overview. (3) We collected evidence on acupuncture and moxibustion for $\mathrm{PD}$, while we failed to separate different types of acupuncture interventions.
4.3. Opportunities for Future Research. Through this overview, we found that current evidence is of low quality; hence, further research is needed. (1) Highquality RCTs with large sample sizes are necessary to demonstrate the safety of different types of acupuncture interventions for PD. (2) RCTs or SRs should follow the corresponding guidelines in their reporting. CONSORT (Consolidated Standards of Reporting Trials) [49] are 


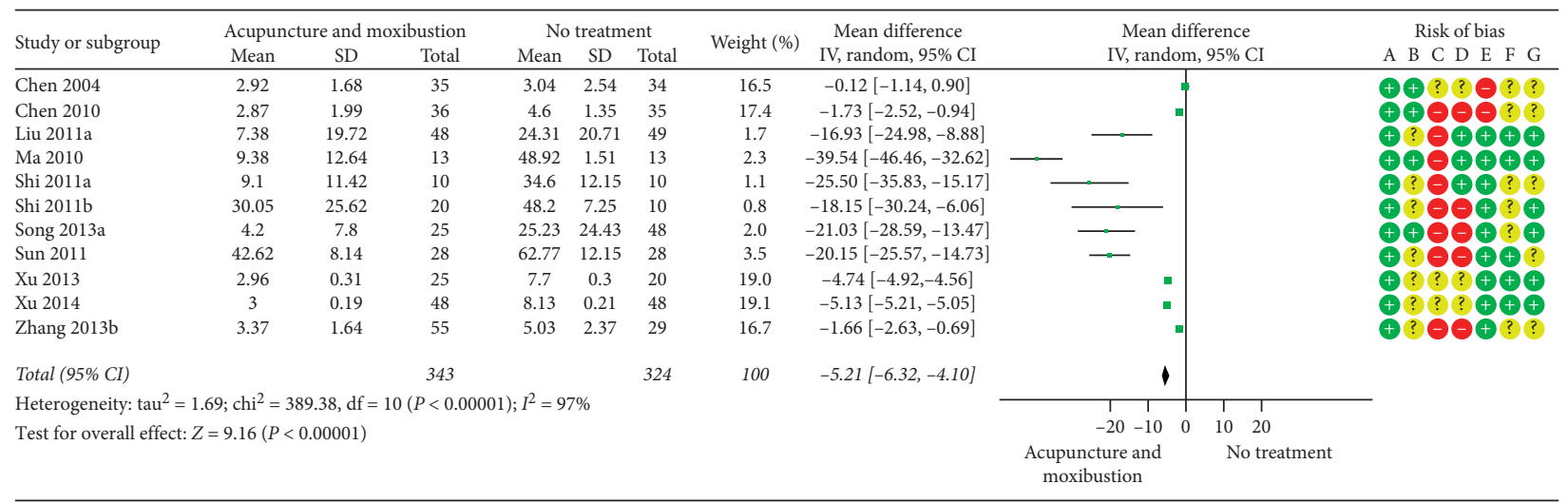

Risk of bias legend

(A) Random sequence generation (selection bias)

(B) Allocation concealment (selection bias)

(C) Blinding of participants and personnel (performance bias)

(D) Blinding of outcome assessment (detection bias)

(E) Incomplete outcome data (attrition bias)

(F) Selective reporting (reporting bias)

(G) Other bias

Figure 8: Acupuncture and moxibustion vs. no treatment.

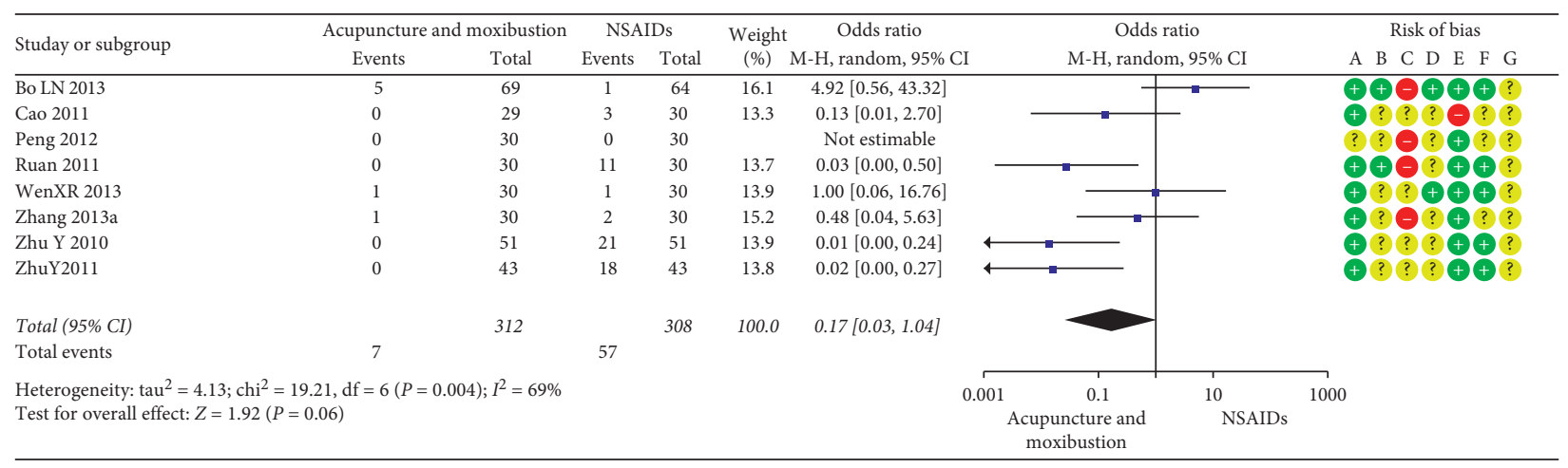

Risk of bias legend

(A) Random sequence generation (selection bias)

(B) Allocation concealment (selection bias)

(C) Blinding of participants and personnel (performance bias)

(D) Blinding of outcome assessment (detection bias)

(E) Incomplete outcome data (attrition bias)

(F) Selective reporting (reporting bias)

(G) Other bias

Figure 9: Acupuncture and moxibustion vs. NSAIDs.

TABLE 5: Quality of evidence in the included studies assessed by the GRADE approach.

\begin{tabular}{|c|c|c|c|c|}
\hline Outcome & Intervention vs. comparison & Included studies & Effect size & Quality of the evidence \\
\hline \multirow{4}{*}{ Total effective rate } & Acupuncture and moxibustion vs. indomethacin & 16 SRs, 22 RCTs & $\mathrm{OR}=3.9,95 \% \mathrm{CI}(2.56,5.95)$ & $\begin{array}{c}\oplus \bigcirc \bigcirc \bigcirc(1) .(2) .(3) \\
\text { very low }\end{array}$ \\
\hline & Acupuncture and moxibustion vs. ibuprofen & 17 SRs, 29 RCTs & $\mathrm{OR}=3.55,95 \% \mathrm{CI}(2.88,4.39)$ & $\begin{array}{l}\oplus \oplus \oplus \bigcirc(1) \\
\text { moderate }\end{array}$ \\
\hline & Acupuncture and moxibustion vs. Fenbid & 12 SRs, 13 RCTs & $\mathrm{OR}=7.68,95 \% \mathrm{CI}(4.98,11.86)$ & $\begin{array}{l}\oplus \oplus \oplus \bigcirc(1) \\
\text { moderate }\end{array}$ \\
\hline & Acupuncture and moxibustion vs. Somiton & 5 SRs, 9 RCTs & $\mathrm{OR}=2.17,95 \% \mathrm{CI}(1.56,3.02)$ & $\begin{array}{c}\oplus \oplus \underset{\mathrm{O}}{\bigcirc} \mathrm{O}(1) \cdot(3) \\
\text { low }\end{array}$ \\
\hline \multirow{3}{*}{ VAS } & Acupuncture and moxibustion vs. NSAIDs & 7 SRs, 17 RCTs & $\begin{array}{c}\mathrm{MD}=-1.96,95 \% \mathrm{CI} \\
(-2.76,-1.17)\end{array}$ & $\begin{array}{c}\oplus \oplus \bigcirc \bigcirc(1) \cdot(2) \\
\text { low }\end{array}$ \\
\hline & Acupuncture and moxibustion vs. sham acupuncture & 5 SRs, 16 RCTs & $\begin{array}{c}\mathrm{MD}=-4.38,95 \% \mathrm{CI} \\
(-6.15,-2.60)\end{array}$ & $\oplus \underset{\text { low }}{\bigcirc}(1) \cdot(2)$ \\
\hline & Acupuncture and moxibustion vs. no treatment & 4 SRs, 11 RCTs & $\begin{array}{c}\mathrm{MD}=-5.21,95 \% \mathrm{CI} \\
\quad(-6.32,-4.10)\end{array}$ & $\begin{array}{c}\oplus \bigcirc \bigcirc \bigcirc(1) .(2) .(3) \\
\text { very low }\end{array}$ \\
\hline Adverse events & Acupuncture and moxibustion vs. NSAIDs & 7 SRs, 8 RCTs & $\mathrm{OR}=0.17,95 \% \mathrm{CI}(0.03,1.04)$ & $\begin{array}{c}\oplus \oplus \underset{\text { low }}{\bigcirc} \text { ○(1).(2) } \\
\text { (2) }\end{array}$ \\
\hline
\end{tabular}

(1) Allocation concealment or blinding inadequate; (2) $I^{2}>50 \%$ or large heterogeneity; (3) funnel plot dissymmetry or language limitation. $\oplus:+1, \bigcirc:-1, \oplus \oplus \oplus$

$\oplus:$ High, $\oplus \oplus \oplus \bigcirc$ : Moderate, $\oplus \oplus \bigcirc \bigcirc:$ Low, and $\oplus \bigcirc \bigcirc \bigcirc$ : very low. 
applied to all kinds of RCTs, and they include some characteristic guidelines such as STRICTA (Standards for Reporting Interventions in Controlled Trials of Acupuncture) [50] and STRICTOM (The Standards for Reporting Interventions in Clinical Trials Of Moxibustion) [51] for acupuncture and moxibustion, independently. PRISMA is used for SR and MA. (3) We also recommend GRADE approach to assess the evidence quality of the more SRs in the future. (4) The primary RCTs should give more attention to blinding, allocation concealment, and registration, which could result in more reliable evidence.

\section{Conclusion}

In conclusion, the current evidence suggests that acupuncture and moxibustion is more effective than ibuprofen or Fenbid in the treatment of PD. While there is no enough evidence to support that acupuncture and moxibustion are safe methods to relieve pain and improve the VAS, future studies should place more emphasis on the safety of acupuncture for PD. Also, more efforts are required to improve the study quality of RCTs and SRs, and researchers should strictly adhere to the CONSORT and PRISMA guidelines.

\section{Abbreviations}

\begin{tabular}{|c|c|}
\hline PD: & Primary dysmenorrhea \\
\hline SR: & Systematic review \\
\hline MA: & Meta-analysis \\
\hline CNKI: & China National Knowledge Infrastructure \\
\hline VIP: & $\begin{array}{l}\text { Chinese Science and Technology Periodical } \\
\text { Database }\end{array}$ \\
\hline AMSTAR2: & A measure tool to assess systematic reviews 2 \\
\hline PRISMA: & $\begin{array}{l}\text { Preferred Reporting Items for Systematic } \\
\text { Reviews and Meta-Analyses }\end{array}$ \\
\hline PRISMA-A: & $\begin{array}{l}\text { Preferred Reporting Items for Systematic } \\
\text { Reviews and Meta-Analyses-Abstract }\end{array}$ \\
\hline GRADE: & $\begin{array}{l}\text { Grading of Recommendations Assessment, } \\
\text { Development, and Evaluation }\end{array}$ \\
\hline CONSORT: & Consolidated Standards of Reporting Trials \\
\hline STRICTA: & $\begin{array}{l}\text { Standards for Reporting Interventions in } \\
\text { Controlled Trials of Acupuncture }\end{array}$ \\
\hline STRICTOM: & $\begin{array}{l}\text { The Standards for Reporting Interventions in } \\
\text { Clinical Trials of Moxibustion }\end{array}$ \\
\hline VAS: & Visual analogue scale \\
\hline NSAIDs: & Nonsteroidal anti-inflammatory drugs. \\
\hline
\end{tabular}

\section{Conflicts of Interest}

The authors declare that there are no conflicts of interest.

\section{Acknowledgments}

The authors would like to thank Professor Xiong who gave methodological guidance on evidence-based medicine and their classmates for their cooperation and hard work. This work was supported by Jiangxi Key Research and Development Program, China (Grant no. 20161BBG70109),
Jiangxi Outstanding Young Talents Funding Scheme, China (Grant no. 20171BCB23093), Project of the National Natural Science Foundation of China (Grant no. 81573835), and Jiangxi Provincial Youth Fund Key Projects, China (Grant no. 20192ACB21007).

\section{Supplementary Materials}

Additional file 1: exclusion list; additional file 2: AMSTAR 2 evaluation of acupuncture and moxibustion for PD; additional file 3: PRISMA evaluation of acupuncture and moxibustion for PD; additional file 4: risk of bias summary; additional file 5: risk of bias graph. (Supplementary Materials)

\section{References}

[1] S. Hailemeskel, A. Demissie, and N. Assefa, "Primary dysmenorrhea magnitude, associated risk factors, and its effect on academic performance: evidence from female university students in Ethiopia," International Journal of Women's Health, vol. 8, pp. 489-496, 2016.

[2] T. S. Midilli, E. Yasar, and E. Baysal, "Dysmenorrhea characteristics of female Students of health school and affecting factors and their knowledge and use of complementary and alternative medicine methods," Holistic Nursing Practice, vol. 29, no. 4, pp. 194-204, 2015.

[3] Y.-T. Chang and Y.-C. Chen, "Menstrual health care behavior and associated factors among female elementary students in the Hualien region," Journal of Nursing Research, vol. 16, no. 1, pp. 8-16, 2008.

[4] S. Zhang, X. Wang, O. zhi et al., "Overview of TCM external therapy for primary dysmenorrhea," Chinese and Foreign Women's Health Research, vol. 23, pp. 24-26, 2017.

[5] X. Zhu, M. Proctor, A. Bensoussan, C. A. Smith, and E. Wu, "Chinese herbal medicine for primary dysmenorrhoea," Cochrane Database Syst Rev, vol. 51, Article ID CD005288, 2007.

[6] X. Guo, X. Liu, and F. Wang, "Clinical application and mechanism of sanyin jiao acupoint," Journal of Jilin Traditional Chinese Medicine, vol. 31, no. 1, pp. 47-48, 2011.

[7] C. shan, "The objective research and the machine of sanyin jiao," in Proceedings of the Thesis Compilation of 2013 Zhejiang Acupuncture Society Annual Meeting and Academic Exchange Conference, pp. 220-225, Zhejiang, China, 2013.

[8] X. Yu, Metabolomics Study on Treating Primary Dysmenorrhea with Moxibustion and Umbilicus, Shandong University of Traditional Chinese Medicine, Jinan, China, 2012.

[9] R. Ren and L. X. Zhuang, "Effect of electricity on blood flow mechanics and hemorheology of uterine artery with primary dysmenorrhea," Chinese Journal of Traditional Chinese Medicine, vol. 28, no. 3, pp. 649-651, 2010.

[10] N. Zhao, G. Ruilin, Q. Ren et al., "The clinical effect of acupuncture on primary dysmenorrhea and the correlation analysis of hemorheology," Journal of Zhejiang University of Chinese Medicine, vol. 31, no. 3, pp. 364-365, 2007.

[11] Y. Xu, W. Zhao, T. Li et al., "Effects of acupoint-stimulation for the treatment of primary dysmenorrhoea compared with NSAIDs: a systematic review and meta-analysis of 19 RCTs," BMC Complement Altern Med, vol. 17, no. 1, p. 436, 2017.

[12] L. Wang, Systematic Evaluation of Sandwiched Moxibustion in Treating Primary Dysmenorrhea, Chengdu University of Traditional Chinese Medicine, Chengdu, China, 2016. 
[13] B. R. Dong, Evidence-based Clinical Practice, People's Medical Publishing House, Beijing, China, 2008.

[14] J. Li and Y. P. Li, "Improving and developing Cochrane systematicreview," Zhongguo Xun Zheng Yi Xu Za Zhi (Chin J EvidBased Med, Chin), vol. 8, no. 9, pp. 742-743, 2008.

[15] C. A. Smith, "Acupuncture for dysmenorrhoea," Cochrane Database of Systematic Reviews, vol. 4, Article ID CD007854, 2016.

[16] F. Zhang, M. Sun, and S. Han, "Acupuncture for primary dysmenorrhea: an overview of systematic reviews," EvidenceBased Complementary and Alternative Medicine, vol. 2018, Article ID 8791538, 11 pages, 2018.

[17] B. J. Shea, B. C. Reeves, G. Wells et al., "Amstar 2: a critical appraisal tool for systematic reviews that include randomised or non-randomised studies of healthcare interventions, or both," BMJ, vol. 358, p. j4008, 2017.

[18] D. Moher, A. Liberati, J. Tetzlaff, and D. G. Altman, "Preferred reporting items for systematic reviews and meta-analyses: the PRISMA statement," Journal of Clinical Epidemiology, vol. 62, no. 10, pp. 1006-1012, 2009.

[19] D. Altman, D. Best, P. A. Briss et al., "Grading quality of evidence and strength of recommendations," BMJ, vol. 328, no. 7457, p. 1490, 2004.

[20] State Administration of Traditional Chinese Medicine, Diagnostic and Therapeutic Criteria for TCM Diseases and Syndromes, China Medical Science and Technology Press, Beijing, China, 2012.

[21] H. Cao, J.-M. Xing, J. Liu et al., "Application of visual analogue scales in assessment of symptomatic outcome data," Journal of Traditional Chinese Medicine, vol. 50, no. 7, pp. 600-602, 2009.

[22] R. D. Hays, C. D. Sherbourne, and R. M. Mazel, "The rand 36item health survey 1.0," Health Economics, vol. 2, no. 3, pp. 217-227, 1993.

[23] Ministry of Health, Guidelines for Clinical Research of New Chinese Medicine, Ministry of Health, Beijing, China, 1993.

[24] S. Y. Yu, Z. T. Lv, Q. Zhang et al., "Electroacupuncture is beneficial for primary dysmenorrhea: the evidence from metaanalysis of randomized controlled trials," Evidence-Based Complementary and Alternative Medicine, vol. 2017, Article ID 1791258, 14 pages, 2017.

[25] T. Xu, "Effects of moxibustion or acupoint therapy for the treatment of primary dysmenorrhea: a meta-analysis," Alternative Therapies in Health and Medicine, vol. 20, no. 4, pp. 33-42, 2014.

[26] Y. Fan, Meta-analysis on the Treatment of Primary Dysmenorrhea by Acupuncture and Moxibustion, Guangxi University of Traditional Chinese Medicine, Nanning, China, 2012.

[27] L. Lan, M. Liu, Y. Tang et al., "Therapeutic effect of acupuncture on primary dysmenorrhea," Journal of Shandong University of Traditional Chinese Medicine, vol. 33, no. 6, pp. 511-514, 2009.

[28] C. Mei, F. Liu, J. Liu et al., "Meta-analysis of clinical study on the treatment of primary dysmenorrhea by heat-sensitive moxibustion," Chinese Medicine Bulletin, vol. 18, no. 1, pp. 31-37, 2019.

[29] H. Xu, C. Lin, X. He et al., "Clinical literature research on the treatment of primary dysmenorrhea with moxibustion based on Meta analysis," Hunan Journal of Traditional Chinese Medicine, vol. 35, no. 3, pp. 124-125, 2019.

[30] K. Wang, M. Zhou, and S. Wu, "Meta-analysis of clinical efficacy of heat-sensitive moxibustion in treating primary dysmenorrhea," Journal of Jiangxi University of Traditional Chinese Medicine, vol. 30, no. 1, pp. 59-62, 2018.

[31] M. Zhou, X. Huang, and R. Chen, "Systematic evaluation/ Meta analysis of heat-sensitive moxibustion therapy for primary dysmenorrhea," Liaoning Journal of Traditional Chinese Medicine, vol. 25, no. 4, pp. 818-822, 2018.

[32] X. Lu, Y. Liu, L. Pang et al., "Meta-analysis of the clinical effect of interposition moxibustion on primary dysmenorrhea," Chinese Journal of Basic Medicine of Traditional Chinese Medicine, vol. 24, no. 7, pp. 983-989, 2018.

[33] H. L. Woo, H. R. Ji, Y. K. Pak et al., "The efficacy and safety of acupuncture in women with primary dysmenorrhea: a systematic review and meta-analysis," Medicine, vol. 97, no. 23, 2018.

[34] L. Tong, Y. Jia-Ni, C. Bing-Yan et al., "Acupuncture for primary dysmenorrhea: a meta-analysis of randomized controlled trials," Alternative Therapies in Health and Medicine, vol. 23, no. 7, 2017.

[35] Y. Fan, Li Lu-qi, S. Gong et al., "Systematic evaluation of the effect of wen acupuncture on primary dysmenorrhea," Evidence Based Nursing, vol. 3, no. 2, pp. 117-122, 2017.

[36] J. Sun, Y. Wang, Z. Zhang et al., "Systematic evaluation of the effect of filiform acupuncture on primary dysmenorrhea," Chinese Acupuncture, vol. 37, no. 8, pp. 887-892, 2017.

[37] Y. Qin, L. Dai, Y. Wang et al., "Meta-analysis based clinical literature on acupuncture and moxibustion for primary dysmenorrhea," Hunan Journal of Traditional Chinese Medicine, vol. 33, no. 8, pp. 162-165, 2017.

[38] C. Gu, Systematic Evaluation of the Effect of Moxibustion Time Factor on the Curative Effect of Primary Dysmenorrhea, Chengdu University of Traditional Chinese Medicine, Chengdu, China, 2017.

[39] L. Tian, W. Hua, X. Xu et al., "Meta-analysis of acupuncture treatment for primary dysmenorrhea," Hunan Journal of Traditional Chinese Medicine, vol. 32, no. 1, pp. 143-146, 2016.

[40] C. Gou, J. Gao, C. Wu et al., "Systematic evaluation of the effect of moxibustion with moxibustion with different moxibustion times on primary dyenorrhea," Evidence Based Nursing, vol. 2, no. 3, pp. 132-138, 2016.

[41] H. Lin, Q. Zeng, D. Liu et al., "Meta-analysis of acupuncture treatment for primary dysmenorrhea," Henan TCM, vol. 35, no. 4, pp. 862-865, 2015.

[42] A. Qin, R. Ma, X. Wan et al., "Systematic evaluation of pure acupuncture and moxibustion-related therapy for primary dysmenorrhea," International Journal of Obstetrics and Gynecology, vol. 41, no. 4, pp. 453-458, 2014.

[43] E. Listijo, Systematic Evaluation of the Effectiveness of Moxibustion Therapy in Treating Primary Dysmenorrhea, Guangzhou University of Traditional Chinese Medicine, Guangzhou, China, 2014.

[44] C. Wen, H. Yu, S. Liu et al., "Systematic evaluation of acupuncture treatment for primary dysmenorrhea in China," Chinese Journal of Traditional Chinese Medicine, vol. 31, no. 2, pp. 321-325, 2013.

[45] H. Yang, Systematic Evaluation of Acupuncture and Moxibustion-Related Therapy for Primary Dysmenorrhea, Beijing University of Traditional Chinese Medicine, Beijing, China, 2008.

[46] M. Chen, L. Chien, C. Liu et al., "Acupuncture or acupressure at the sanyinjiao (SP6) acupoint for the treatment of primary dysmenorrhea: a meta-analysis," Evidence-Based Complementary and Alternative Medicine, vol. 2013, Article ID 493038, 8 pages, 2013. 
[47] Y.-C. Chung, H.-H. Chen, M.-L. Yeh et al., "Acupoint stimulation intervention for people with primary dysmenorrhea: systematic review and meta-analysis of randomized trials," Complementary Therapies in Medicine, vol. 20, no. 5, pp. 353-363, 2012.

[48] S.-H. Cho and E.-W. Hwang, "Acupuncture for primary dysmenorrhoea: a systematic review," BJOG: An International Journal of Obstetrics \& Gynaecology, vol. 117, no. 5, pp. 509-521, 2010.

[49] K. F. Schulz, D. G. Alt man, and D. Moher, "CONSORT2010 Statement: updated guide-lines for reporting parallel group randomised trials," Trials, vol. 11, p. 32, 2010.

[50] J. Gagnier, H. Boon, P. Rochon et al., "Standards for reporting interventions in controlled trials of acupuncture:The STRICTA recommendations," Complementary Therapies in Medicine, vol. 9, no. 4, pp. 246-249, 2001.

[51] C.-W. Cheng, S.-F. Fu, Q.-H. Zhou et al., "Extending the CONSORT statement to moxibustion," Journal of Integrative Medicine, vol. 11, no. 1, pp. 54-63, 2013. 